\title{
Management of sinistra condyle fracture in emergency: case report
}

\author{
Cahyadi Siauw, ${ }^{1 *}$ Asri Arumsari, ${ }^{2}$ Endang Syamsudin, ${ }^{3}$ Fathurachman ${ }^{4}$
}

\section{Abstract}

Objective: Condyle fracture is a fracture that involves temporomandibular joint, resulting temporomandibular joint disorder. It often caused complications namely ankylosis and temporomandibular joint disorder. Trauma induced mandible fracture can leads to unilateral or bilateral condyle fracture.

Method: Nine teen years old male came with mouth bleeding and pain on left lower jaw joint. Clinical examination showed laceration on right chin and left condyle fracture.
Result: Management of patient to stitch laceration wound on chin region. Condyle fracture was treated conservatively using closed reduction method by arch bar and MMF rubber.

Conclusion: Condyle fracture management needs a particular concern using closed method or conservative and open method or surgery. This present case chose closed method referring minimal displacement of condyle fracture.

Keywords: Condyle fracture, Closed reduction, Arch bar

Cite this Article: Siauw C, Arumsari A, Syamsudin E, Fathurachman. 2018. Management of sinistra condyle fracture in emergency: case report. Journal of Dentomaxillofacial Science 3(3): 184-187. D0I: 10.15562/jdmfs.v3i3.735

'Department of Oral and Maxillofacial Surgery, Faculty of Dentistry / Dr. Hasan Sadikin General Hospital, Padjadjaran University, Bandung, Indonesia

${ }^{2}$ Department of Oral and Maxillofacial Surgery, Dr. Hasan Sadikin General Hospital, Padjadjaran University, Bandung, Indonesia ${ }^{3}$ Department of Oral and Maxillofacial Surgery, Faculty of Dentistry, Padjadjaran University, Bandung, Indonesia

${ }^{4}$ Department of Orthopaedic, Dr. Hasan Sadikin General Hospital, Bandung, Indonesia
"Corresponding to: Cahyadi Siauw, Department of Oral and Maxillofacial Surgery, Faculty of Dentistry/Dr. Hasan Sadikin General Hospital, Padjadjaran University, Bandung, Indonesia cahyadiandroid@gmail.com

Received: 9 April 2018

Revised: 6 June 2018

Accepted: 9 July 2018

Available Online: 1 December 2018

\section{Introduction}

Mandible fracture is described as a bone structure disruption on mandible. ${ }^{1}$ Mandible fracture induced by trauma usually caused either unilateral or bilateral condylar fracture. Not only occlusion is the main target of treatment, but 'fracture union' can be the main target. ${ }^{2}$

Mandible fracture location is based on anatomy region involved; symphysis, parasymphysis, body, angle, condyle and coronoid. Its treatment needs a particular consideration compared to the other fracture treatments. ${ }^{3}$

The following report describes a condylar fracture management using closed reduction in the Emergency Department.

\section{Case Report}

Nine Teen years old male referred from a hospital in Cimareme with mouth bleeding and pain on closing mouth. His head was examined and the chin wound was stitched temporarily there, also given antibiotic and analgesic. Oral Surgery and Maxillofacial Department examination revealed a good general condition, compos mentis, and scored 15 on GCS, there was abrasive and laceration wound extraorally and deformity on left face figure $1 \mathrm{~A}-\mathrm{B}$.

Management in the ER began with anti-tetanus serum and toxoid tetanus injection to prevent tetanus infection because the patient had the accident at dirty place. Then the IV line was set with $0.9 \% \mathrm{NaCl}$ solution and he was sent to the laboratory for routine blood test, PT, aPTT, Skull AP-lateral xray, trauma series $\mathrm{x}$-ray and focused assessment Sonography in Trauma (FAST examination) figure 2. It was confirmed from the examination that there was bone discontinuity on left condyle. He was planned for resuturing on right chin, maxilla and mandible interdental wiring, closed reduction with MMF rubber and bite riser. Bite riser set at ER was done with ice cream stick figure 3-5A and 5B.

\section{Classification}

Condylar fracture was classified according to Lindahl based on several factors, namely fracture anatomic location, condyle relation to mandible, condyle head relation to glenoid fossa. This classification system needs at least two radiographic images from correct angles. ${ }^{1}$

\section{Condylar fracture level}

Head of condyle. Though it is hard to define the head of condyle precisely on radiograph, it is easy to see condyle neck constriction and condyle head leans at top of it. Condylar fracture, according to the definition, is an intracapsular fracture because the capsule is adhered to the neck. It may be considered as vertical fracture, neck of condyle. Condyle neck is a thin constricted area below the head. ${ }^{2}$

\section{Condyle segment relation to mandible segment}

Non diplaced, deviated. This fracture type has the fragment in contact without separation or overlap, 


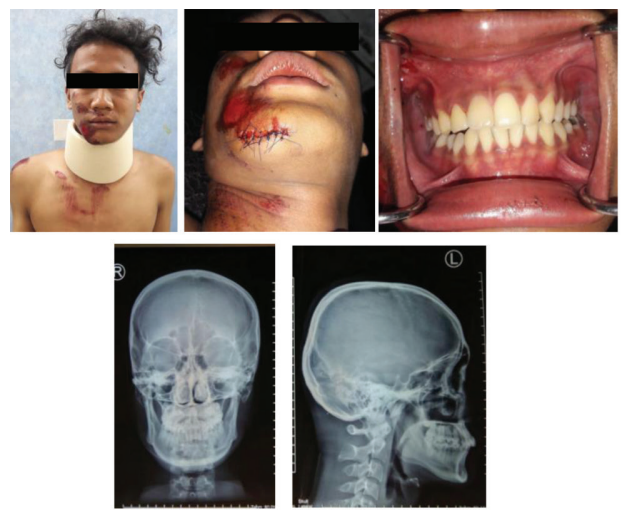

A
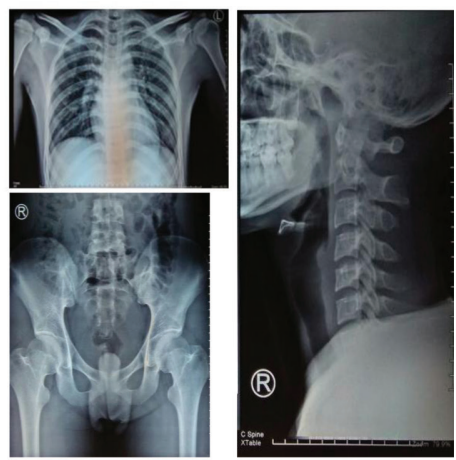

B

Figure 1 A. Profile picture, situasional suture, intraoral condition and Skull AP- Lateral $\mathrm{x}$-ray, B. Trauma series $\mathrm{x}$-ray (thorax $\mathrm{x}$-ray, cervival $\mathrm{X}$-ray, pelvic $\mathrm{x}$-ray)
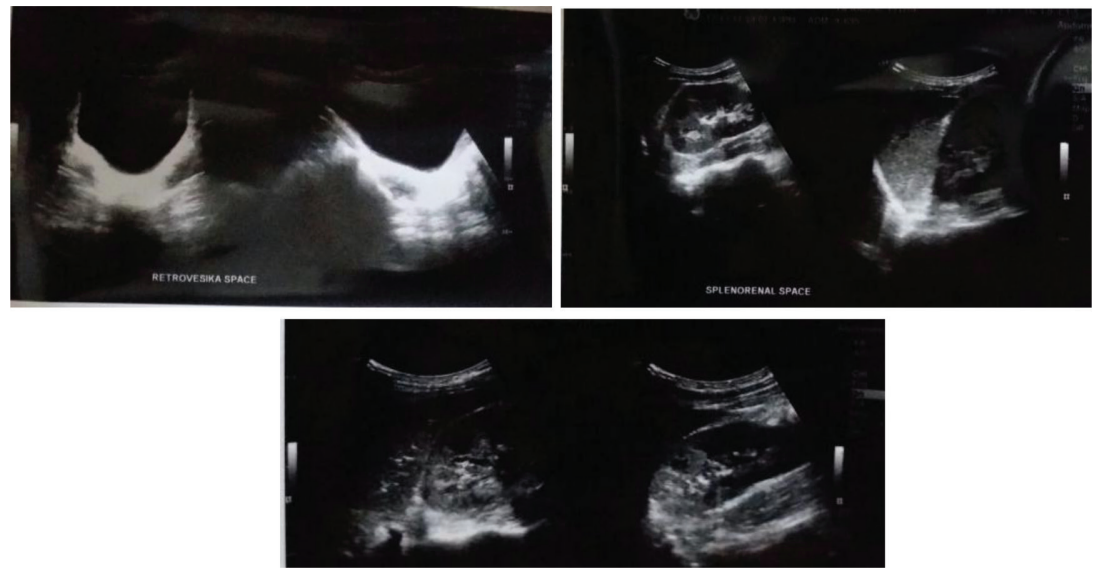

Figure 2 USG FAST (Foccused Assestment Sonography in Trauma)
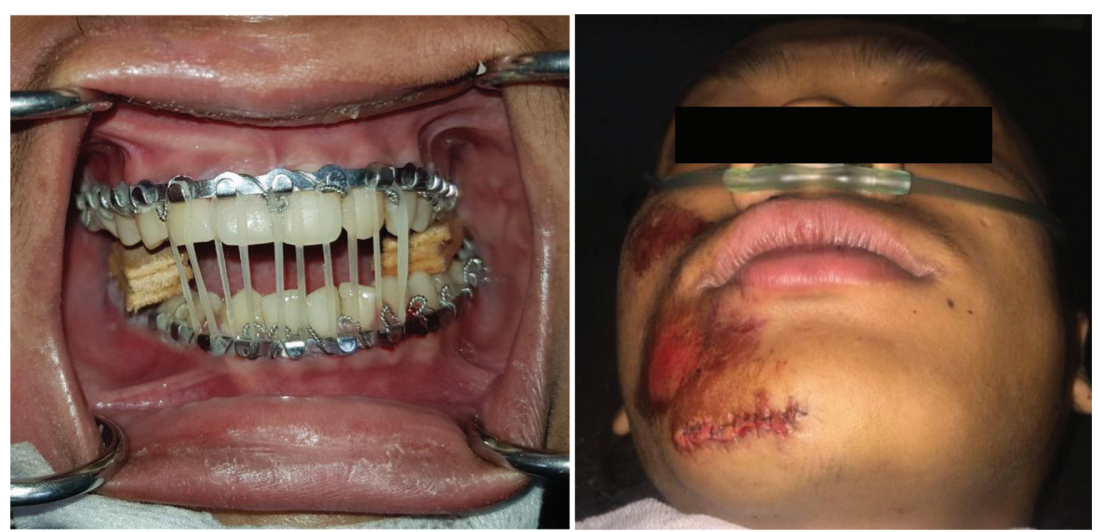

Figure 3 MMF rubber and bite riser was set at emergency and resuturing at chin region

medial displacement or lateral overlap. Lateral pterygoid muscle pull caused fragment displacement medially, anterior displacement or posterior overlap, no contact between the fractured segments. ${ }^{2}$

\section{Condyle head relation to glenoid fossa}

Nondisplaced. Condyle head has a normal relation to glenoid fossa, displacement. Condyle head left

in the fossa, joint disorder is evident, dislocation. Lateral pterygoid muscle pull caused the condyle segment moved anteromedially. ${ }^{2}$

\section{Treatment}

Management of mandible condylar fracture is controversial, mainly caused by a lot of modalities offered according to several literatures. Main goal of condylar fracture management is to restore mastication system function, this reconstruction involves fracture segment relation, occlusion and maxillofacial balance. It can be done conservatively or closed method and surgery or open method. ${ }^{1,3}$

\section{Closed method or conservative}

Fonseca suggests that complication during conservative treatment is very rare. Conservative management is indicated if the displacement is minimal or no displacement or the fracture line is too high, making it difficult to be stabilized using surgery. Conservative management for condylar fracture is very simple. It needs a strict monitoring to observe occlusion instability, deviation on mouth opening, increased pain, clinical and radiograph evaluation. Immobilization involves intermaxillary fixation (IMF) using arch bar, eyelet wire or splint. Its average duration is between 7 to 21 days and can be prolonged or shortened depends on patient's age, degree of displacement and additional fracture. After the intermaxillary fixation is removed, use elastic guidance to direct the mandible to maximal intercuspation position. Then, after functional ability is restored and the occlusion is stabilized and pain is minimal, elastic guidance and arch bar are removed. ${ }^{1,3}$

\section{Open Method or surgery}

It is indicated if: condyle displaced into media cranial fossa, impossible to achieve an optimal occlusion using closed method, lateral extracapsular dislocation of the condyle, bilateral condylar fracture in edentulous patient, bilateral or unilateral condylar fracture if splinting is not recommended due to patient's general condition or physiotherapy is difficult, bilateral condylar fracture due to midface comminuted fracture, mandible condyle ankylosis caused by trauma and delayed treatment ${ }^{1,3,5,8}$

There are 3 separated techniques for rigid fixation related to condylar fracture management using open method, Luhr bicortical system with vitallium plate, Arbeitgemeinschaff for Osteosynthesefragen System Association for the Study for Internal Fixation (AO/ASIF) using stainless steel compression or reconstruction plate with bicortical screws and champy miniplate technique used along line of ideal osteosynthesis with moncortical screws. $^{5}$ 


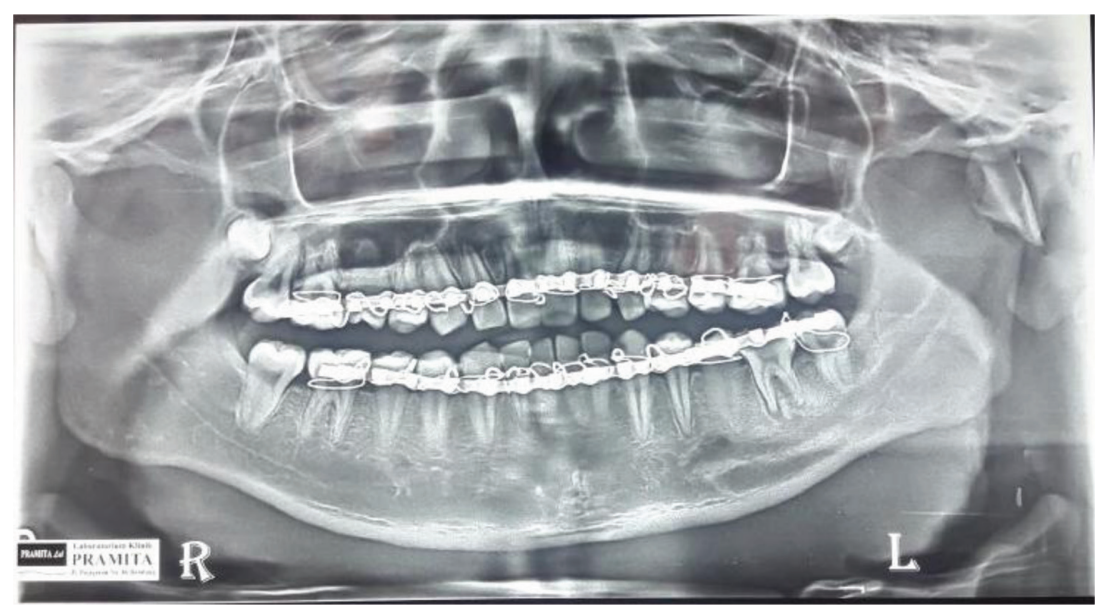

Figure 4 Panoramic radiograph evaluation post-emergency; left condylar fracture was revealed with displacement
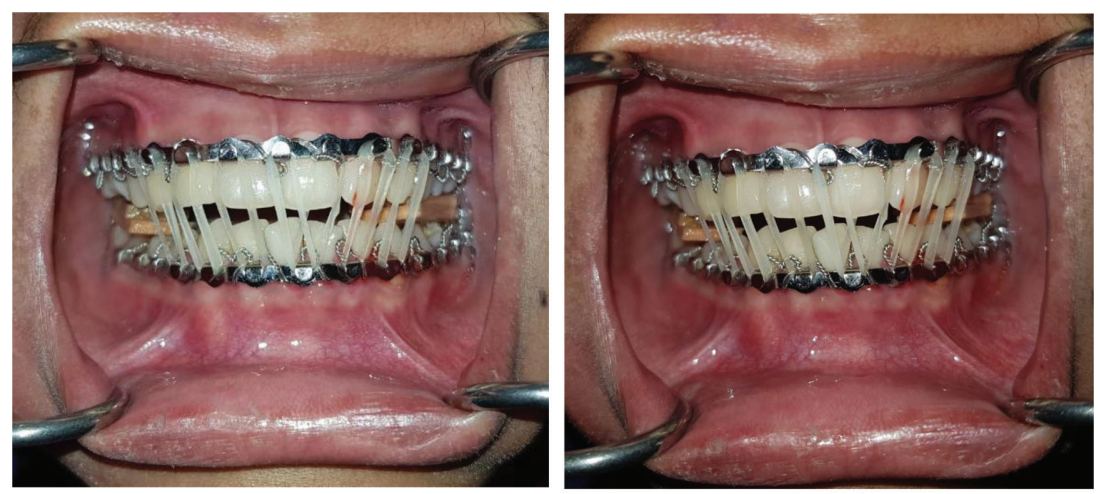

A

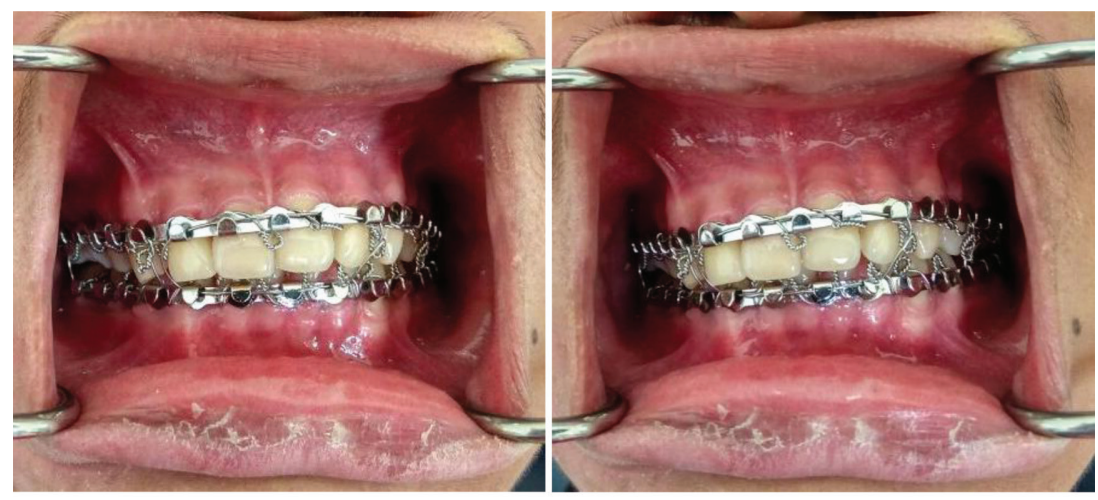

B

Figure 5 A. Follow up after 1 week and 2 weeks; bite riser was reduced, B. Follow up after 3 weeks and 4 weeks, MMF wire was set and occlusion was normal

IMF is used for 3 weeks, tighten every week, then after it is removed, evaluate the temporomandibular joint especially mouth opening distance, mandible movement, and signs showed during functional. If the occlusion is not stabilized yet, elastic guidance is recommended for 2-3 weeks to achieve neuromuscular adaptation. After the occlusion is stabilized, elastic guidance is removed followed by physiotherapy using tongue-blade between central incisors to prevent permanent ankylosis limitation. ${ }^{1,3}$

Condylectomy is another technique to relieve ankylosis and maintain temporomandibular joint structure. It shows several success and rarely caused re-ankylosis. Intermaxillary fixation is applied in short term, followed by strict monitoring along with physiotherapy for a year.

Approach method used for condylectomy is pre auricular approach, endaural approach, inverted 'hockey stick' approach, Risdon approach, post auricular approach. ${ }^{3}$

\section{Complication}

Mandible condyle fracture complication during treatment is very rare. ${ }^{1,3,5,7}$

Temporomandibular joint ankyloses, growth disturbance, post osteoarthritis traumatic, other temporomandibular joint disorder (ex: internal derangement).

\section{Discussion}

Type and direction of trauma is very helpful to establish the diagnosis. Object causing the fracture also affects the type and number of fracture, if the object is large, it could cause fracture in 1 or more location and on the contrary, it could cause one type of fracture because the impact force is concentrated in one location. ${ }^{1}$

Knowledge of impact force direction can help to establish the right type of fracture. Anterior blow directly to the chin can result a bilateral condylar fracture, while a blow to parasymphysis can result a contralateral condyle or angle fracture. A patient with occluded teeth when the impact took place can result alveolar or teeth fracture. ${ }^{1}$

All occlusion changes are signs of mandible condylar fracture. Clinical examination has to confirm the patient whether the occlusion is different. Occlusion change is resulted from teeth, alveolar and mandible fracture at any location and from trauma on temporomandibular joint and mastication muscles. Premature contact at posterior teeth or open bite at anterior teeth can be caused by bilateral condyle or angle fracture. Retrognathic occlusion is usually related with condyle or angle fracture and prognathic occlusion can be seen clearly in temporomandibular joint fracture. These examples are only a few of multiple occlusion disharmony seen, however every occlusion changes need to be considered as the early sign of mandible condylar fracture. ${ }^{1}$ Patient with mandible condylar fracture usually has a limited opening. However, a true mandible condylar fracture or related with facial fracture results an abnormal mandible movement. 
Deviation on mouth opening to the fractured condyle side is one of the classic sign. Functional lateral pterygoid muscle on the unaffected side is not neutralized by non functional lateral pterygoid muscle on the affected side, resulted a deviation. Condyle and body fracture with displacement can inhibit lateral mandible movement.

Clinical examination should check face and mandible with abnormal contour however the facial contour may be covered with swelling. Long face appearance resulted from subcondylar, angle, or body fracture followed with down mandible displacement. Facial asymmetry should be noticed for condylar fracture possibility. ${ }^{1}$

Through examination in missing teeth and supporting bone may help to diagnose alveolar, body, and symphysis. Clinician should use both hands with thumbs placed on the teeth and forefingers on lower border of mandible carefully, then put some pressure between both hands to detect fracture crepitation. ${ }^{1}$

Localized pain, redness, swelling, and hotness are the early signs of trauma and increased mandible fracture suspicion. ${ }^{1}$

\section{Conclusion}

Mandible condyle fracture needs an immediate management based on exact diagnosis, thus reducing or eliminating complication risk. ${ }^{2}$

\section{Acknowledgment}

The author would like to thank the patient and my lecture who has been willing to share his case for reported.

\section{Conflict of Interest}

The authors report no conflict of interest.

\section{References}

1. Fonseca RJ. Oral and maxillofacial trauma. 2nd ed. London: W.B. Saunders Company; 1997. p. 473-567.

2. Goldman KE. Fractures mandible, condylar and subcondylar. eMed J 2015;2: 1-13.

3. Barrera JE. Mandibular body fracture. eMed J 2002;3: 1-11.

4. Bustomi AF, Sylvyana M, Syamsudin E, et al. Parotid gland tuberculous abscess. J Dentomaxillofac Sci 2016;1: 185-189.

5. Chaudhary A. Temporomandibular joint syndrome. eMed J 2002;3: 1-9.

6. Tucker SR. Ankylosis of TMJ. Oral \& Maxillofac Surg J 2002;3 : 1-3.

7. Widell T. Fractures mandible. eMed J 2001;2: 1-16.

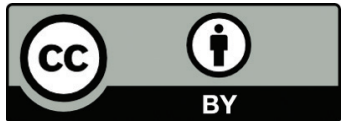

This work is licensed under a Creative Commons Attribution 